\title{
LUT
}

University

\section{Improved Knowledge Changes the Mindset: Older Adults' Perceptions of Care Robots}

\author{
Johansson-Pajala Rose-Marie, Thommes Kirsten, Hoppe Julia, Tuisku Outi, \\ Hennala Lea, Pekkarinen Satu, Melkas Helinä, Gustafsson Christine
}

This is a Final draft version of a publication

published by Springer Nature

in Human Aspects of IT for the Aged Population. Design for the Elderly and Technology Acceptance. HCII 2019. Lecture Notes in Computer Science.

DOI: 10.1007/978-3-030-22012-9_16

Copyright of the original publication: () Springer Nature Switzerland AG 2019

Please cite the publication as follows:

Johansson-Pajala, R.-M., Thommes, K., Hoppe, J., Tuisku, O., Hennala, L., Pekkarinen, S., Melkas, H., Gustafsson, C. (2019). Improved Knowledge Changes the Mindset: Older Adults' Perceptions of Care Robots. In: Zhou, J., Salvendy, G. (eds) Human Aspects of IT for the Aged Population. Design for the Elderly and Technology Acceptance. HCII 2019. Lecture Notes in Computer Science, vol 11592. pp. 212-227. DOI: 10.1007/978-3-030-22012-9_16

This is a parallel published version of an original publication. This version can differ from the original published article. 


\title{
Improved Knowledge Changes the Mindset: Older Adults' Perceptions of Care Robots
}

\author{
Rose-Marie Johansson-Pajala ${ }^{1}$, Kirsten Thommes ${ }^{2}$, Julia A. Hoppe ${ }^{2}$, Outi Tuisku ${ }^{3}$, \\ Lea Hennala ${ }^{3}$, Satu Pekkarinen ${ }^{3}$, Helinä Melkas ${ }^{3}$, Christine Gustafsson ${ }^{1}$ \\ ${ }^{1}$ Mälardalen University, Eskilstuna/Västerås, Sweden \\ ${ }^{2}$ Paderborn University, Paderborn, Germany \\ ${ }^{3}$ Lappeenranta University of Technology, Lahti, Finland
}

\begin{abstract}
This paper explores Finnish, German and Swedish older adults' perceptions of a future welfare service with increased use of welfare technologies, specifically care robots. The issues are the rapid digitalization and development of health and welfare technology, which presently is mainly technology driven (not need or user driven), and the demographic challenge. The aim of the study was to explore older adults' perception of the future use of welfare technology or care robots. A qualitative approach with focus group discussions was employed, followed by thematic analysis. The results are presented in four overall themes: the impact on daily life for older adults and professional caregivers, codes of practice and terms of use, dissemination of information and knowledge, and conditions for successful implementation. There were significant differences in the informants' attitudes toward and knowledge about care robots. However, the informants' attitudes appeared to change during the focus groups and in general, became more positive. Authentic needs, which care robots could support, refer to independence, safety and security, and the ability to manage or ease daily life or working life. The results suggest that older adults, after receiving relevant information, were open to the idea of being supported by care robots in their daily lives.
\end{abstract}

Keywords: Care Robots, Older Adults, Implementation, Information, Perceptions, Welfare Technology

\section{Introduction}

The number of older adults is growing rapidly throughout the world. These demographic changes will increase the need for health care services, but the number of people who can provide and finance these services is decreasing [1, 2]. Health technology, such as welfare technology, has been launched as a means of meeting these challenges $[2,3]$. Different types of welfare technology are also changing the traditional health care organization. Welfare technology introduces technology in new spaces, such as private homes, and it provides new functions, such as offering social stimuli and entertainment [3]. This technology could make it possible for older adults to live longer in 
familiar surroundings, to have quick remote communication with professional caregivers if needed, and to have a (remote) physical examination in their homes [4]. The purpose of this paper was to provide a cross-country inventory (Finland, Sweden and Germany) of older adults' perceptions of a future welfare service with increased use of welfare technologies, in particular care robots, for support in daily life. The term care robots includes machines that operate partly or fully autonomously while performing care-related activities for people with disabilities, physical or mental, that are related to age or health restrictions [5]. In this paper, the term care robots refers to robotic technology that can be used to support older adults and care workers in providing physical, cognitive, or emotional support [6].

\section{Elder Care and Welfare Technology}

\subsection{The Changing Landscape of Elder Care}

Elder care, in particular, is facing a gigantic shift in technology and the demographic challenge of an aging population. In the near future, the relative population of older adults in Western Europe will increase because of aging and increased life expectancy [7]. By 2050, globally the number of people older than 60 years is expected to be higher than the number of people younger than 15 years [8]. We also live in a period of rapid digitalization and health and welfare development. Old technology such as the telefax machine required about 150 years from the time the patent was approved until the product was available on the market compared to the contemporary time to market of about 1 to 2 years [9]. Welfare technology is expected to help people live a healthy life with retained integrity. This technology is also expected to contribute to efficiency in elder care services and meet individuals' needs in living independently. The demographic challenge means that the older population is growing and the working population is decreasing $[10,11]$. Thus, the elder care sector must evolve, and introducing welfare technology might be the most effective method.

\subsection{Acceptance of Care Robots}

In welfare technology, robots have acquired cognitive functions and possibilities for improved safety, which makes it possible to use them to provide new services for the primary users. Although care robots have great potential for health and welfare, the area is challenging due to ethical and social issues $[12,13]$ and the strong role of legislation. In addition, the public has a negative attitude toward the use of robots in elder care [14, 15]. To reap benefits, changes are needed at all levels of the individual-services-society axis and across them. Technological and in particular, service innovations that combine human and cognitive robotic skills might have high potential for easing care professionals' work and providing autonomy for older adults. These goals, however, can be achieved only if all stakeholders accept the new technology. Acceptance and the impact of digital technologies, such as care robots, on older adults who require elder care have implications for the possibilities of rooting technological innovations in care [5]. The way in which older adults are involved in the emerging area of care robots is essential 
for their health, well-being, and opportunities to learn and participate in society throughout the different stages of later life. Technology use is often a major change, but if planned carefully, technology may provide a welcome addition in services. In the area it is also recognized that the health of older adults can be promoted, sustained, and improved with technical aids $[16,17]$, but usable indicators of good welfare technology solutions for older adults are lacking [18]. The most significant factor related to the introduction of technology that motivates an individual is the benefit that he or she gets from using it.

The different types of impact of technology use are often indirect and difficult to identify. The skill levels of individuals differ, and a technical device is not born and used in a vacuum in care: Behind the technology, there is a user with his or her own values, living (or working) environment, and related service activities [19]. Technologies are still typically used in care services as separate 'islands' and a systemic view is missing. Moreover, the perspective of older adults is often neglected.

\subsection{Meeting User Needs}

Older adults as technology users are often viewed stereotypically or represented by assumptions or static identities, without cultural and historical constructions [20]. The benefits of robots and technology in elder care are often embedded in a specific set of claims, such as an aging population with rising care costs, a decreasing qualified workforce, and the desire of older adults to live independently as long as possible [21, 22]. Older adults are mostly positioned as having deteriorating health and needing costly care. In this narrow portrayal of older adults, old age is strongly related to illness, frailty, lost competences, and high costs. If these kinds of images underlie development processes, including the orientation phase, then the resulting technologies, for example, care robots, may implicitly or explicitly position older users as frail, ill, or in need of care [22]. If the design is based on stereotypical and homogenous sociocultural images of older adults, it may reinforce this imagery and translate into key design decisions [23]. If diversity in users is incorporated at all, it is most often only age and gender differences [24]. Moreover, today's older adults might differ from future generations of older adults, for instance, regarding acceptance of technology for social needs and the strong Western cultural value of being independent, which might be an incentive to use robots in daily life. There is often an imbalance between perceptions of older adults' technology needs and knowledge about their actual needs. The supposed user uses technology according to the manufacturer's idea of how the item should be used. However, this is distinct from the real user, who is actually using the technology and may, for instance, change its purpose [25]. According to Östlund et al. [20], the role of older adults in digital agendas may be simply to legitimize development for fictive users rather than real ones. Another aspect is that older adults are much more discerning than the manufacturers of robots for older adults believe. Frennert [26] found that older adults want to know what robots can do for them and are not interested in a service robot if it does not add anything useful. Many manufacturers have a view of older adults as passive recipients, and the stereotype of older adults governs robot development. 
Age-based assumptions that lie at the heart of technology design and implementation are maintained by ideologies that are resistant to change [27].

In Neven's [22] study that tested health care robots, participants' views did not influence the designers' overall view of elderly users. As designers and technology developers seem to rely on stereotypical views of gender and age, user diversity is neglected [23]. Old age is seen as a homogeneous stage in life, yet it covers tens of years and includes several phases. There is a need for a paradigm shift and proactive technology that meets the needs and demands of today's actual senior citizens [20], such as the robotic cat for people with dementia (JustoCat) [28, 29]. The changed view of older adults as heterogenic welfare technology users involves analysis of the explicit and implicit interactions among technology, designers, and users. A field study of the implementation process of the care robot Zora in Finland showed that robot use affects customers and their family members in many ways that are positive, negative, and neutral. For instance, the robot stimulated users to exercise and led to reminiscing because of its child-like character. The robot also created various new interactions with the customer or between customers and professional caregivers. This study also highlighted that customers should not be misled; the role of ethics is a key issue [30].

Rationale. The overarching aim of this paper was to explore older adults' perceptions of the use of welfare technologies, in particular care robots, for support in daily life. The issue is important because of the rapid digitalization and development of health and welfare technology, which is mainly technology driven (not needs or user driven), and the demographic challenge the global society is facing. The specific aims were to explore how older adults perceive care robots in elder care and how they discuss the introduction/implementation of care robots in elder care.

\section{Method}

\subsection{Design}

A qualitative approach with focus groups was employed. Focus group discussions are particularly suited to the study of attitudes, perceptions, and experiences. The interaction within the groups can help people explore and clarify their own attitudes in ways that would be less accessible in individual interviews [31, 32].

\subsection{Setting and Recruitment}

The present study is part of the ORIENT project under the Joint Programming Initiative 'More Years, Better Lives'. The ORIENT project focuses on orientation, introduction to technology use, and learning of different skills for effective use in the spirit of cocreation. Partners from three European countries (Finland, Germany, and Sweden) participate in the project. Various perspectives are considered within the project, such as the perspectives of older adults, older adults' family members, professional caregivers, 
and care service organizations. Societal and other stakeholders' (such as business, industry, public administration, and the nonprofit sector) perspectives are also included in the project.

The focus of this paper is the perspective of older adults who live at home. Purposeful sampling was used to recruit the informants. Recruitment was conducted through verbal and written requests to retirement organizations and through contacts. The inclusion criterion was that the informants should have an interest in the field, and variations in gender were also strived for.

\subsection{Focus Groups}

An interview guide was developed by the research team consisting of opening, introductory, and transition questions, followed by key questions [32]. One focus group was conducted in Sweden and Finland, and two focus groups were conducted in Germany, with four to seven informants in each group, for a total of four focus groups. In total, 24 older adults participated in the focus groups. The participants all lived in their own housing and did not receive help from home care services (Table 1).

Table 1. Informants' demographic data.

\begin{tabular}{llll}
\hline Characteristics & Finland & Germany & Sweden \\
\hline Women/men & $3 / 1$ & $8 / 6$ & $5 / 1$ \\
Age, mean (range) & $75(70-81)$ & $68.6(60-79)$ & $72.5(69-75)$ \\
Highest level of education & & & \\
$\quad$ University & 0 & 4 & 6 \\
Secondary school & 3 & 0 & 0 \\
Vocational education & 1 & 9 & 0 \\
Elementary school & 0 & 1 & 0 \\
\hline
\end{tabular}

Informed consent was obtained from all informants before the focus groups were held. Two to three researchers were present during the focus groups, one acting as a moderator and the others as assistant moderators. The focus groups were conducted in the informants' native language. Each focus group began with an introduction and description of the purpose of the discussion. Then, the moderator followed the interview guide, moving from general to more specific questions, and showed a short video and pictures that exemplified various types of care robots. The interview guide was used to ensure consistency between the different countries (Table 2). The focus groups lasted for 60140 minutes and were audio recorded. The recordings were then transcribed verbatim and processed as texts. 
Table 2. Interview guide.

\begin{tabular}{|c|c|}
\hline Introduction question & $\begin{array}{l}\text { Brainstorm about the use of and need for welfare technology in elder } \\
\text { care. }\end{array}$ \\
\hline Transition question & $\begin{array}{l}\text { Thoughts about the use/introduction of robotic technology in elder } \\
\text { care. Should we use robots in elder care? }\end{array}$ \\
\hline Key questions & $\begin{array}{l}\text { Display of a short video ( } 3 \text { minutes) and pictures, exemplifying var- } \\
\text { ious types of care robots (used for service and support in daily life, } \\
\text { such as social, physical, and mental stimulation and communica- } \\
\text { tion). } \\
\text { - } \quad \text { Reflections on the video and pictures; benefits and disad- } \\
\text { vantages from different perspectives. } \\
\text { Additional questions: } \\
\text { - How would you feel about being cared for or assisted by a } \\
\text { care robot when you get old and require help? } \\
\text { - Do we, in general, need to know more about care robots? } \\
\text { What? Why? How? By whom? } \\
\text { If you would like to learn more about care robots, what would } \\
\text { you do? } \\
\text { How should the use of care robots be introduced in elder care, } \\
\text { and what training is required? }\end{array}$ \\
\hline Ending question & $\begin{array}{l}\text { Reflection on what was said during the discussion; does anything } \\
\text { need to be added? The assistant moderator is invited to reflect or } \\
\text { ask additional questions. }\end{array}$ \\
\hline
\end{tabular}

\subsection{Analysis}

The focus group discussions were analyzed using an inductive thematic analysis with a semantic approach [33]. The six phases consist of becoming familiar with the data, generating initial codes, searching for themes, defining and naming themes, and producing the report. Accordingly, the transcribed text was read and reread to capture the features associated with the research topic. The sentences and paragraphs, assessed as interesting or meaningful in relation to the phenomenon under study, were identified and marked, and initial codes were systematically generated across the entire data set. This first part of the analysis was performed in the original language and by the research team in each of the three countries. Then, all text (the codes) was translated into English, and the rest of the analysis was carried out by two researchers (RMJP and CG), though all authors reflected on the data during the process. The codes were grouped together into potential themes and sub-themes. The relevance of the themes was checked in relation to the codes and the entire data set. Finally, clear definitions and names for each theme were identified. The analysis resulted in four overall themes and 13 sub-themes (Table 3). 
Table 3. Sub-themes and themes revealed in the analysis.

\begin{tabular}{ll}
\hline Sub-themes & Themes \\
\hline $\begin{array}{l}\text { Independence and safety } \\
\text { Physical and mental assistance } \\
\text { Communication and socialization } \\
\text { Complement to human resources }\end{array}$ & $\begin{array}{l}\text { Impact on daily life for } \\
\text { older adults and profes- } \\
\text { sional caregivers }\end{array}$ \\
$\begin{array}{l}\text { The individual's right to decide } \\
\text { Expected functions }\end{array}$ & $\begin{array}{l}\text { Codes of practice and } \\
\text { terms of use }\end{array}$ \\
$\begin{array}{l}\text { Introduction to technology earlier in life } \\
\text { Tailored information }\end{array}$ & $\begin{array}{l}\text { Dissemination of infor- } \\
\text { mation and knowledge }\end{array}$ \\
$\begin{array}{l}\text { Multiple channels for information } \\
\text { Convincing professional caregivers }\end{array}$ & $\begin{array}{l}\text { Conditions for success- } \\
\text { ful implementation }\end{array}$ \\
$\begin{array}{l}\text { Multi-level collaboration } \\
\text { Cost allocation }\end{array}$ & \\
\end{tabular}

\section{$4 \quad$ Results}

Four overall themes, including 13 sub-themes, illustrated older adults' perception of the future use of care robots. The term welfare technology is used alternately with care robots, because what kind of welfare technology the informants referred to was not always specified. The results are presented in themes and by underlying sub-themes. Quotes from the interviews, provided in the sub-themes, are marked with a letter ( $\mathrm{S}, \mathrm{F}$ or $\mathrm{G}$ ) indicating the country of origin.

\subsection{Impact on Everyday Lives of Older Adults and Professional Caregivers}

This theme covers older adults' perceptions of different areas where welfare technology or care robots could have an impact in their daily lives or support and improve the delivery of care.

Independence and Safety. Welfare technology was perceived to provide conditions for prolonging the ability to live independently. The ability to manage by oneself implies maintained autonomy and integrity. "I would like to have a robot that can help me pick up stuff, open the fridge...instead of somebody coming to help me, so I can decide 
for myself"'(S). Care service, perceived as threatening integrity, for example, in having support with hygiene, could preferably be provided by some kind of welfare technology. However, opposing views also appeared in the discussions, indicating rejection of the use of such technology and the claim that human attention is preferred. Welfare technology was also considered to ensure safety in different ways, for example, related to monitoring functions as sending health data (e.g., blood pressure and blood glucose levels), and distributing medication.

Physical and Mental Assistance. One common perception was that welfare technology could facilitate practical tasks at home, for example, doing household chores, picking up objects from the floor, and cleaning. Welfare technology that enables mobility was also discussed as useful. "Yes, so if I had difficulties to move around at home and do household chores, I would probably accept it [a robot]" (F). Supporting people with cognitive impairments was also mentioned as a possible area of use.

Communication and Socialization. Possibilities for communication with professional caregivers were perceived as beneficial. Welfare technology could then be useful for receiving information quickly. For example, a video connection in a robot could make it easier to get help from health care organizations. Professional caregivers, such as physicians, could be supported in detecting health incidents and in diagnosing patients. However, welfare technology with monitoring functions was viewed critically by some informants. Furthermore, technology could facilitate communication with family members, something that would be beneficial for both parties. Opportunities for a social life would also increase. "...so it facilitate [for older adults] a social life, if I cannot get out, then society can come in" (S). One perception was that welfare technology could enrich the daily lives of older adults, especially those in care homes, where it could be used for mental stimulation, entertainment, and different activities, such as reading and playing music.

Some informants would have conversations with robots while others would not. Similar disagreements existed in the case of social robots. Some perceived that a social robot could reduce feelings of loneliness, while others rejected the use of robots for social interaction. One concern was the risk that those who are not capable of handling the welfare technology could become even lonelier.

Complement or Replacement for Human Resources. Many informants perceived the technology as a complement to professional caregivers. By using this technology, professional caregivers would have more time for the older adults, and the human resources would be used where they were required. "My spontaneous reaction is, welfare technology, yes, it gives staff more time, and they can spend that time with the older adult needing support" $(G)$. The informants suggested that robots could assist care professionals in different ways, for example, with personal hygiene, cleaning, and physically heavy work. Informants also suggested that technology could be helpful in the event of a shortage of professional caregivers. However, a major concern was whether professional caregivers would be replaced by technology. The informants felt that there was 
an imminent risk that this could occur, partly because in the end, technology is cheaper than human labor. However, some informants emphasized that there are situations where people cannot be replaced by technology. For example, a robot cannot provide human warmth, or act as a substitute for interpersonal relations, or provide psychological support. "...the technology cannot replace interpersonal relations..." (G).

\subsection{Codes of Practice and Terms of Use}

This theme describes regulations of practice needed when welfare technology or care robots are offered to older adults. Aspects of expected functions and usability are also addressed.

The Individual's Right to Decide. Regulations related to the implementation of welfare technology in care for the elderly were an important issue. A common perception among the informants was that each individual should be allowed to decide whether to use welfare technology or not. Some people wanted human hands, and some preferred welfare technology. Thus, welfare technology should not be forced upon older adults. There must be sensitivity in assessing when welfare technology is appropriate to use and when it is not. For instance, the use of welfare technology was discussed in relation to older adults with cognitive impairment, such as people suffering from dementia. Some perceived that welfare technology would work well for these persons, while others thought it was not appropriate. "...but for people suffering from dementia, I find it shameful and inhuman to use robots" $(G)$. In contrast to the perception that welfare technology use should be optional, some informants thought that it should not always be possible to choose. Not everything can be optional, and sometimes, people just need to be told that this is the way of doing things. "This is how nursing is done, this is the help we offer you, if it is cameras, help to turn off the stove...there are a lot of things like that" (S). For health care services, an individual's actual needs are the basis for the assessment.

Expected Functions. This sub-theme mirrors different aspects of the expected functions and the usability of welfare technology artifacts. During the discussion, it was evident that some participants had high expectations for what care robots should be capable of doing (the expected functions). For example, the robots should recognize emotional situations and act accordingly. The robots should also be able to work autonomously, make suggestions, and have the function to have conversations. If the robot were dependent on additional instructions from professional caregivers, then the caregivers could perform the task themselves. "I think, if an expensive nurse or trainee has to stand behind the robot and give instructions, it somehow seems pointless..." (G). One informant expressed a fear of robots eventually making decisions independently. The question of safety was also a concern for some informants. In the case of malfunctions, there must be some kind of security system, to ensure that no human being comes to harm. 


\subsection{Dissemination of Information and Knowledge}

This theme explores the general and societal needs for improving the introduction of welfare technology or care robots, as well as suggestions for orientation activities.

Introduction of Technology Earlier in Life. Welfare technology should be introduced earlier in life, before the actual need arises. When people become affected by old age and illnesses, it is difficult for them to make their own decisions. "Inform as early as possible, before you develop dementia, it do not have to be dementia, it can also be physical and intellectual disabilities" (S). Although an early introduction to welfare technology is preferred, older adults often do not perceive the information as interesting or necessary, until changes in their own life conditions occur. "... since I do not think I need it [care robots] at the moment, I do not even know what to ask for and what kind of information I would need" (F). However, with the gradually increasing use of welfare technology in society, it will eventually become more common and accepted. Some informants expressed that for future generations the use of welfare technology will likely constitute a natural part of life.

Tailored Information. Information about welfare technology must reach those concerned, older adults. To make decisions, one needs to know what kind of welfare technology is offered and what it can do or assist with. The acceptance of welfare technology depends on the level of information, and good examples need to be disseminated. For example, the term "robot" must be clarified as it has a negative connotation and is perceived as alienating and inhuman. The informants expressed that when welfare technology is offered to older adults, special attention should be paid to its introduction. Welfare technology should be taught in a way that suits older adults, and it should be ensured that they really grasp it. When young people give instructions, they often do it too fast, which makes older adults feel slow, and thus, they give up trying to understand the technology. "...when it comes to technology, I can manage, but it goes too fast [instructions]...For us older adults, technology should be taught in such a way that people understand" $(F)$.

Different perceptions prevailed about who should provide information about available welfare technology. Some thought that information should be given by official sources or professional caregivers. Others thought sources for information could be friends, health insurance funds, the manufacturers of the technology, and consultants.

Training on Welfare Technology and Trust. Older adults need information and training that enable them to trust welfare technology. Concerning robots, this could involve practical training in how to use them, as well as how to approach and speak to a robot. Training could also involve environmental and security issues. "They [robots] can also do something wrong or have a malfunction, just like humans do...you have to try to limit that so that no patient [older adult] will be injured" (G). Some older adults were concerned about data security, how their data would be protected, and how they could have control over their data. 
Multiple Channels for Information. Several suggestions were given regarding how to disseminate information about welfare technology. Welfare technology should be visible to create demand. Television was a common suggestion as practically every household has one. Other means for disseminating information could be social media, fairs, through senior citizens' associations, storytelling, shops, and similar places where many people pass by. Some informants pointed out that using welfare technology must be pleasurable and exciting. In addition, there should be opportunities to test it in real life, that is, learning by doing. Another suggested channel for disseminating information was through research and education; for instance, universities should offer education in robots. According to some informants, the prevailing attitude among today's professional caregivers is that there should be human hands, not welfare technology, an attitude that could change through education.

\subsection{Conditions for Successful Implementation}

This theme describes the conditions identified as important for the successful implementation of welfare technology and care robots in the elder care context.

Convincing Professional Caregivers. For the implementation to succeed, professional caregivers must be convinced and positive about the use of welfare technology. They should not perceive welfare technology as something separate; instead, it should be an integrated part of nursing care. "Convince the professional caregivers, how we can do it, I do not know, but it has to be done" (S). Some informants suggested that some caregivers could receive special training in welfare technology use. Then they could act as digital assistants and support other caregivers, as well as older adults.

Multi-level Collaboration. Successful implementation of welfare technology for older adults would require collaboration at multiple levels. The informants perceived that a whole chain of decisions and actions probably were required, ranging from legislation and public organizations to interest organizations and older adults themselves. Some informants pointed out that welfare technology should be developed in consultation with older adults. Their needs should form the basis for what technology is needed and produced; subsequently, they, relatives and professional caregivers, should be involved in the process. "I think it [welfare technology] is the future. We cannot use the old system forever...but the older adults have to be taken into account when this is implemented, and their relatives as well" (F).

Cost Allocation. The question of who should pay for welfare technology was a major concern among the informants. Should society bear the costs or older adults themselves, or perhaps should the costs be divided? "It is the municipality's responsibility to pay, if the robot is absolutely necessary...those who have a high salary can pay for the robot by themselves" (F). If so, how should the line be drawn between what is accessible to everyone and what is considered to add extra value? One fear was that the technology 
would cause further divisions in society, implying that only those with resources would have access to the technology. In contrast, some informants claimed that society cannot pay for everything, and people with the financial resources can pay for the welfare technology themselves.

\section{Conclusions, Limitations and Implications}

\subsection{Increased knowledge changes attitudes}

The focus group discussions in the present study revealed significant differences in the informants' attitudes toward and knowledge about welfare technology and care robots: Some were negative and others positive. It is not that the attitudes in general were negative. However, the context of elder care seems to have an impact on their standpoints. This seems to make the use of care welfare technology or care robots questionable, which can be interpreted as whether the use of robots in elder care is not as accepted as in other areas of healthcare, as also shown by, for instance, Eurobarometer [34]. However, the attitudes appeared to change during the focus group discussion. Some informants even expressed that they had a negative attitude when they arrived, but it changed, mainly due to the increased knowledge and because they understood what care welfare technology and care robots are and how they can support daily life. As the results suggest that older adults are open to the idea of being supported by welfare technology or care robots in their daily lives when people have relevant information, we interpret the result as meaning that there is a general urgent need for an improved orientation within the field. This also applies to family members and professional caregivers, as they are the main users in the elder care context and are involved in the implementation processes.

However, all studies have several limitations. In the present study one limitation is that informant recruitment was conducted by purposeful sampling. Many of the informants were people interested in the subject welfare technology and care robots, given that we cannot state having informants representing the full population. Another aspect to highlight is that the informants in a majority were women. On the other hand, participating informants were interested and had something to discuss and say about the issue. This also refers to the present result showing that a negative attitude can change when having increased knowledge. Another weakness in the data, which were collected in three different countries all having different cultures and welfare systems, and importantly different languages. All these aspects have impact in the analysis, in the overall and contextual understanding. The final analysis were led by the Swedish team, this might had the consequence that culture and language specific nuances can be lost in that process, this were not further explored in the full research team.

\subsection{Implementation of care robots in elder care}

Examining the themes that appeared in the present study, it becomes clear that welfare technology and care robots, which are "knocking on the door" to be implemented in 
modern elder care, have important aspects that must be considered for successful implementation.

User involvement to meet authentic needs. One aspect is that welfare technology and care robots must have a considerable impact on users (older adults, family members, or professional caregivers) in improvements in daily life or daily working life. The authentic needs in which welfare technology or care robots could support improvements, according to the present results, are independence, safety and security, and the ability to manage or ease daily life or working life. Considering welfare technology in care for the elderly, authentic needs should play a more central role. Having the point of departure in authentic needs is described as crucial when developing health and welfare technology in this context [28]. End-user participation in developmental activities (co-creation) is one of the basic principles of user-centered methods [35]. Early and ongoing user involvement and participatory methods have been recognized [36] as one of the principles that are particularly important in health information technology [37, 38]. Robots have somewhat different characteristics compared to other technologies in elder care, such as embodied characters, which may provide emotional attachments. Studying the acceptance and use of robots may require consideration of other factors not included in the most frequently utilized technology acceptance models, such as social and hedonic factors $[30,39]$. The structure of elder care is also different from other co-creation processes: Not only is the customer involved but also family members and professional caregivers.

We suggest closer collaboration and the integration of users' different perspectives to achieve a comprehensive view of authentic needs, user involvement, and technology possibilities when welfare technology and care robots are developed. All three perspectives should be emphasized equally for a successful development process. Regarding representative and collaboration obstacles, we understand the challenges, although they must be expressed and solved. Elder care representatives, must, for example, learn to identify and communicate authentic needs of elder care that can be solved by care robots and welfare technology. This refers to the overall aim to free up time in favor of care that really needs human affection, which is considered one solution for meeting the demands of the demographic challenge [7, 8].

Meeting the needs of information and knowledge. There are expectations that the use of welfare technology and care robots should solve some of the problems of the demographic challenge. However, it is naïve to believe it is simple to implement care robots and welfare technology in elder care. Elder care is complex, and there are many aspects that must be respected. For example, there are conditions that must be clarified on different levels in the welfare system, for example, regulations that allow free choice to reject welfare technology or care robots. The question of financial responsibilities must also be clearly communicated, an aspect that was evident in the present results. Another important issue is the dissemination of information and knowledge about the possibilities and support that welfare technology and care robots use offer, an urgent aspect that must be resolved before the implementation can proceed successfully. Nilsen et al. [40] found that when welfare technology is implemented, resistance appears to play a productive role when the implementation is organized as a co-creation process. 
Implementation of welfare technology must be carefully planned and organized for successful results. For older adults and family members as users, storytelling is a powerful method that could complement the official authority practitioner's (care manager's) information [41]. Storytelling in different media, which have the target groups as readers, could be a strategy for meeting the information and knowledge aspects. Raappana, Rauma, and Melkas [42] found that most of the negative effects of welfare technology use could have been eliminated or relieved with a good orientation, based on previous information and assessment. Without an appropriate level of skills and knowledge, feelings of insufficiency and incapability arise, leading to decreased motivation and distress, and may mitigate the impacts on well-being that are pursued.

For innovators working in elder care, it is important to remember that the digital experiences and competences of today's and future generations of older adults most likely will differ [9]). This also refers to the rapid development of technology in general in modern society. Again, this points to the importance of involving the potential users and the right users in the development processes. When including potential users, the categorization of older adults might not be enough. More nuanced inclusion processes for users in the groups of today's and future users are recommended. In our understanding, the results indicate that today's older adults with sufficient and relevant information and knowledge of the possibilities of care robots and welfare technology, in general, have positive perceptions of being future users. However, we as representatives of welfare technology and care robots in elder care have an important and desired mission to develop the content for an effective orientation to welfare technology and care robots in elder care.

Acknowledgments. This study was supported by the ORIENT project under the JTC 2017 launched by JPI MYBL. The support of the JPI MYBL and the national funders within the JPI MYBL framework is gratefully acknowledged (award no. 2017-02300 by Forte, Sweden; award no. 16SV7954 by the Federal Ministry of Education and Research, Germany, and award no. 318837 by the Academy of Finland).

\section{References}

1. Scherer, J. M.: Technology adoption, acceptance, satisfaction and benefit: integrating various assistive technology outcomes. Disabil Rehabil Assist Technol. 12(1), 1-2 (2017). doi:10.1080/17483107.2016.1253939

2. Hoffman, B.: Ethical challenges with welfare technology; a review of literature. Sci Eng Etics. June. 19(2), 389-406 (2013). doi:10. 1007/s 11948-011-9348-1

3. Nordic Centre for Welfare and Social issues. Focus on welfare technology. 2010 Retrieved from https://nvc.brandfactory.se/Files/sv-SE/9047/RelatedFiles/Velferdsteknologi_eng.pdf

4. Harrefors, C., Sävenstedt, S., Axelsson, K.: Elderly people's perception of how they want to be cared for: an interview study with healthy elderly couples in Northern Sweden. Scand J Caring Sci. 23(2), 353-60 (2009). doi: 10.1111/j.1471-6712.2008.00629.x

5. Goeldner, M., Herstatt, C., Tietze, F.: The emergence of care robotics - A patent and publication analysis. Technol Forecast Soc. 92, 115-131 (2015). doi: org/10.1016/j.techfore.2014.09.005 
6. Glende, S., Conrad, I., Krezdorn, L., Klemcke, S. Krätzel, C.: Increasing the acceptance of assistive robots for older people through marketing strategies based on stakeholders needs. Inter J Soci Robot. 8, 355-369 (2016).

7. United Nations Department of Economic and Social Affairs, Population Division. World population ageing 2015. (ST/ESA/SER.A/390) [cited 2018 June 26]. Retrieved from: http://www.un.org/en/development/desa/population/publications/pdf/ageing/WPA2015_Report.pdf

8. United Nations. World Population prospects. 2015 (1) Retrieved from http://esa.un.org/unpd/wpp/Publications/Files/WPP2015_Volume-I_ComprehensiveTables.pdf.

9. Porras, J., Heikkinen, K., Kinnula, M., Sørensen, L., Hennala, L., Melkas, H., Pekkarinen, S., Jefferies, N.: User 2020 - A WWRF Vision. A white paper of the Wireless World Research Forum. 14/2014.

10. Swedish Ministry of Health and Social Affairs. Den ljusnande framtid är vård. Delresultat från LEV-projektet Stockholm: Regeringskansliet; 2010 [cited 2018 November 29]. Retrieved from: https://www.regeringen.se/rapporter/2010/06/s2010.021/

11. ZEW, Monitoring-Report: Digital Economy 2012 - Added Value for Germany [cited 2018, November 29] Retrieved from: https://www.zew.de/en/publikationen/monitoring-reportdigital-economy-2012-added-value-for-germany/

12. Lin, P., Abney, K., Bekey, GA. (eds.). Robot Ethics: The Ethical and Social Implications of Robotics. Cambridge: The MIT Press (2014).

13. Seibt, J., Hakli, R., Nørskov, M. (eds.). Sociable Robots and the Future of Social Relations. Frontiers in Artificial Intelligence and Applications, vol. 273. IOS Press (2014).

14. Tuisku, O., Pekkarinen, S., Hennala, L., and Melkas, H. (In Press): 'Robots do not replace a nurse with a beating heart' - The publicity around a robotic innovation in elderly care. Inf Tech People.

15. Sharkey, A., Sharkey, N.: Granny and the robots: ethical issues in robot care for the elderly. Ethics Inf Technol. 14(1), 27-40 (2012).

16. Herstatt, C., Kohlbacher, F., Bauer, P.: Silver product design - product development for older people. Working Paper No. 65. Hamburg, Germany: Institute for Technology and Innovation Management, Hamburg University of Technology (2011).

17. Kanoh, M., Oida, Y., Nomura, Y., Araki, A., Konagaya, Y., Ihara, K., Kimura, K.: Examination of practicability of communication robot-assisted activity program for elderly people. Robot Mechatron. 23(1), 3 (2011).

18. Taipale, V. T.: Global trends, policies and gerontechnology. Gerontechnology 12(4), 187193 (2014). doi.org/10.4017/gt.2014.12.4.001.00

19. Melkas, H.: Effective Gerontechnology Use in Elderly Care Work: From Potholes to Innovation Opportunities. In: Kohlbacher, F., Herstatt, C. (eds.), The Silver Market Phenomenon: Marketing and Innovation in the Aging Society, pp. 435-449. Springer, Berlin \& Heidelberg (2011).

20. Östlund, B., Olander, E., Jonsson, O., Frennert, S.: STS-inspired design to meet the challenges of modern aging. Welfare technology as a tool to promote user driven innovations or another way to keep older users hostage? Technol Forecast Soc Change. 93, 82-90 (2015). doi.org/10.106/j.techfore.2014.04.012

21. Sparrow, R., Sparrow, L.: In the hands of machines? The future of aged care. Minds Mach. 16(2), 141-161 (2006). doi.org/10.1007/s11023-006-9030-

22. Neven L.: 'But obviously not for me': Robots, laboratories and the defiant identity of elder test 
users. Sociol Health Ill. 32(2), 335-347 (2010). doi.org/10.1111/j.1467-9566.2009.01218.x

23. Oudshoorn, N., Neven, L., Marcelle S.: 'How diversity gets lost. Age and gender in design practices of information and communication technologies'. J Women Aging. 28(2), 170-185 (2016). doi.org/10.1080/08952841.2015.1013834

24. Flandorfer, P.: Population ageing and socially assistive robots for elderly persons: the importance of sociodemographic factors for user acceptance. Int J Popul Res. (2012). doi.org/10.1155/2012/829835

25. Dekker, E.: 'Robot Zora: Friend or Foe? An Exploratory Study about the Emotional Attachment of Elderly to Robot Zora' (2015). Retrieved from http://arno.uva.nl/cgi/arno/show.cgi?fid=606146

26. Frennert, S.: Older People Meet Robots: Three Case Studies on the Domestication of Robots in Everyday Life. Doctoral dissertation. Lund: Department of Design Sciences, Faculty of Engineering, Lund University (2016).

27. Ginn, J., Arber, S.: 'Only connect': Gender relations and ageing. In Arber, S. and Ginn, J. (eds.). Connecting gender and ageing. A sociological approach. Open University Press, Buckingham, pp. 1-14 (1995).

28. Gustafsson, C.: Utveckling och implementering av välfärdsteknologi inom demensvård. Palliativ Omsorg 4(32) 26-30 (2015).

29. Gustafsson, C., Svanberg, C., Müllersdorf, M.: Using a robotic act in dementia care -a pilot study.

J Gerontol Nurs. 41(10), 46-56 (2015).

30. Melkas, H., Hennala, L., Pekkarinen, S., Kyrki, V.: Human impact assessment of service robot implementation in Finnish elderly care. ICServ2016. The 4th International Conference of Serviceology. Tokyo, Japan, September 6-8, (2016).

31. Kitzinger, J.: Qualitative Research: Introducing focus groups. BMJ 311:299 (1995). doi.org/10.1136/bmj.311.7000.299

32. Krueger, R.A., Casey, M.A.: Focus group: A practical guide for applied research. Thousand Oaks, Ca: Sage Publications (2015).

33. Braun, V., Clarke, V.: Using thematic analysis in psychology. Qual Res Psychol. 3(2), 77101 (2006)

34. European Commission (2015), "Special Eurobarometer 427: autonomous systems", technical report, European Commission. Retrieved from: http://ec.europa.eu/commfrontoffice/publicopinion/archives/ebs/ebs_427_en.pdf.

35. Kristensson, P., Matthing, J., Johansson, N.: Key strategies for the successful involvement of customers in the co-creation of new technology-based services. Int J Serv Ind Manag. 19(4), 474-491 (2008).

36. Elg, M., Engström, J., Witell, L., Poksinska, B.: Co-creation and learning in health-care service development. J Serv Manage 23(3), 328-343 (2012).

37. Nambisan, P.: Enabling consumer-driven service innovation in health care: The role of online Health Information Technologies (HIT). In Information technology and product development (pp. 159-177). Springer US (2010).

38. Ghulam Sarwar Shah, S., Robinson, I.: User involvement in healthcare technology development and assessment: structured literature review. Int J Health Care Qual Assur. 19(6), 500515 (2006).

39. Parviainen, J., van Aerschot, L., Särkikoski, T., Pekkarinen, S., Melkas, H., Hennala, L.: Motions with emotions? A double body perspective and human-robot interaction in elderly care. International Research Conference Robophilosophy 2016/TRANSOR 2016: Aarhus, Denmark, October 17-21 (2016). 
40. Nilsen, E,.Dugstad,J., Eide, H., Knudsen Gullslett, M., Eide, T.: Exploring resistance to implementation of welfare technology in municipal healthcare services - a longitudinal case study. BMC Health Services Research BMC series - open, inclusive and trusted 16(657) (2016). doi.org/10.1186/s12913-016-1913-5

41. Haigh, C., Hardy, P.: Tell me a story - a conceptual exploration of storytelling in healthcare education. Nurse Educ Today. 31(4), 408-411 (2011). doi.org/10.1016/j.nedt.2010.08.001

42. Raappana, A., Rauma, M., Melkas, H.: Impact of safety alarm systems on care personnel. Gerontechnology 6, 112-117 (2007). doi:10.4017/gt.2007.06.02.006.00 